Patient-doctor relationships

\section{How to look after your patients by looking after yourself}

R Persaud

\section{Doctors and patients need to realise the mutual benefits of a good relationship}

$\mathrm{t}$ is sometimes said that the vocation of being a doctor would be simply marvellous if it wasn't for the patients-who seem to get in the way of doing one's job properly. Repeatedly the literature suggests that a major cause of burnout in professions that involve much dealing with the public is the emotional demands of such encounters. Yet despite the new emphasis on patient communication in various medical curricula the problem remains that it seems stubbornly difficult to train the problem away for doctors.

Is this perhaps because there is no best way of dealing with patients and attempts to teach some kind of gold standard-some perfect way of being with patients-is ultimately doomed? All of us have a tendency, linked to our personality, to be best able to undertake certain kinds of relationships, while others defeat us. So knowing what kinds of patients we can cope with and who we have more difficulty with, appears to be the kind of experiential learning we may need to discover for ourselves. Otherwise we end up with patients most suited to us personally, while those who find us difficult simply drift towards our colleagues.

An additional but related issue is that the doctor-patient relationship has never fully recovered from Freud because he placed the difficulty in dealing with impossible patients squarely at our door.

Before the advent of psychoanalysis, patients went to doctors who administered a treatment, perhaps a tablet or a procedure. The relationship between physicians and client was not the primary issue; it wasn't unimportant, but it remained merely a mechanism that facilitated delivery of the treatment. After the Freudian revolution, crucially the relationship between doctor and patient could itself become the actual prescription.

An affiliation with an analyst was therapeutic because it was corrective-it compensated for the difficult or traumatic relationships the patient had previously experienced. But is it now a doctor's remit to provide the kind of positive supportive relationship that is difficult to find elsewhere, even in the modern neighbourhood and family? Even if doctors were willing to shoulder this project the public should beware, Harold Shipman was after all, by many accounts, popular with his patients.

In Freudian analysis much of the work of the "doctor" is to think hard and analyse the nature of the relationship that develops with the client, and perhaps feedback some of these interpretations and insights to the analysand. The doctor even has to relentlessly question their personal emotional reactions to the patient, and analyse those.

This in turn meant that the analyst had to undergo their own analysis partly to ensure the doctor-patient relationship could survive the physician's own neuroses. This relationship thing was getting complicated.

The latest data find that those doctors who emotionally care most for their patients are also most likely to become burnt out and suffer severe psychological dysfunction as result, with one fifth of young doctors displaying prominent mental health problems. ${ }^{1}$ It's the doctors who cared emotionally least for patients who seemed most resilient to the stress of seeing them according to this recent

Doctors themselves rate approximately $15 \%$ of all patient encounters in primary care as "difficult" from an emotional standpoint. ${ }^{2}$ A recent survey of 200 British general practitioners (GPs) conducted by NOP for Readers Digest magazine found half say that what they really want to tell their patients is that they should wash before coming to see them. Fifty percent of GPs also wish they could say to patients "You say you've taken your medication, but I don't believe you".

Common requests from doctors for their patients include "please don't answer your mobile phone while I am giving you a smear test". Two thirds want to tell their patients they are too fat, but the GPs are so frustrated with being treated like "supermarket research. assistants" they are usually unable to hint at what they really think of their patients.

Patients on the other hand are described in qualitative studies as having to work extremely hard to get doctors to take their suffering seriously. ${ }^{3}$

It looks as though things are getting so critical in the doctor-patient relationship that divorce might even be imminently on the cards.

There is now a body of research supporting the increased use of technology like computers to take over many of the roles of the doctor, given the recent reliable finding that computers are superior to uncovering more sensitive information when history taking than doctors. $^{4}$

Therapy by email is apparently rapidly spreading across the Atlantic partly because therapists who provide this service point out a great advantage to themselves is in an increasingly litigious clinical atmosphere: it is impossible to be sued for sexual abuse by clients if one delivers therapy by this method.

The traditional authority or role of the doctor within the relationship with patients is also under threat-the latest model for the consultation is "evidence based patient choice" where the central principle is that doctors should become more "patient centred".

Here the conventional medical appointment is transformed to provide patients with evidence based information in a way that facilitates their ability to make choices or decisions about their health care. The model emphasises respect for patient preferences, their involvement in health care decisions, and advocates the sharing of medical information rather than the more traditional role of guidance by the doctor-a reflection of the supposed imbalance in expertise and experience of the clinician. It's all about "empowering" patients. ${ }^{5}$

However definitive scientific evidence that the patient centred consultation is superior to the more traditional model is difficult to find, even when measures like "patient satisfaction" are at the heart of measurement.

Yet medical education still tends to put the disease rather than the patient at the centre of what doctors' work is meant to be primarily about. Despite surveys finding that the average doctor spends at least half their working day talking to patients, the relationship with patients occupies still a relatively marginal place in medical training, in comparison with the biological study of pathology. ${ }^{7}$ Changes are only now being considered mainly because the rise of the internet and other technologies means access to information-though 
often of dubious quality-means patients now can feel as informed as doctors.

But surely unless the patient themselves attend medical school there will always be at the heart of medicine a fundamental difference between the "illness" -what the patient believes is wrong with them and how they feel about it—and the "disease" — the doctor's diagnosis or identification of the pathology. It is the conflict that this inevitably sets up that surely underpins much of the difficulties in the doctorpatient relationship.

From the patients' standpoint not enough has been done by physicians to educate the public on the increasing difficulty of being a doctor today in terms of implicit conflicts in our role embodied by the "disease"//"illness" distinction. Patients want an authority figure, a friend, a confidante and a technical expert, but also someone who will not stand in the way of the patients' own choices no matter how difficult they make the doctors' own job. This fails to fully comprehend the "disease" / "illness" contrast that lies at the heart of the idea that medical training socialises doctors away from a lay appreciation of the body.

Actually the idea that doctors don't think about bodies in the same way patients do is probably deeply disturbing to most patients-so they prefer not to properly confront this fundamental issue.

Also contrasting patients at distinct stages of their lives and illnesses probably require different kinds of relationships with their doctors. Not everyone wants to see a physician who knows them well and intimately. While a recent review of the benefits of continuity of care from the Institute of General Practice at Exeter University found continuity improves the uptake of preventive care, treatment adherence and patient satisfaction, there were surprisingly ambiguous results when it came to the effect on disease prognosis. ${ }^{8}$ Younger and male patients in particular were found to not value continuity of care. $^{8}$

It would seem that doctors need a mechanism for uncovering what particular kind of relationship a patient might require during this particular consultation, but to baldly inquire after this seems to render the encounter awkward and mechanistic.

Perhaps both doctors and patients need to become more aware that each side probably has a repertoire of relationships they are capable of, just as we are all able to have a different association with our grandmothers compared with our girlfriends. Maybe then both can learn to constantly but subtly negotiate what kind of alliance is best suited to them, after all this delicate dance is precisely what happens at the commencement of most intimate relationships, and is never an entirely unproblematic choreography. This explains widespread relationship phenomena like heartbreak and stalking.

At the heart of strong associations is each party having a good sense of how the other feels-or empathy. It is notable then that a significant number of doctors aren't themselves registered with GPs. Perhaps one of the most profound elements of a doctor's education is to get to feel what it is like to be a patient. This brings us back full circle to the Freudian idea that every clinician should themselves have their own analyst, a notion that perhaps was abandoned too soon.

The dawn of a new century coincides with upheaval in the public availability of medical information and the mechanisms of delivery of healthcare, so we are definitely entering a new stage in the doctor-patient relationship, whatever either side might prefer or think. If doctors and patients are to enjoy a second honeymoon, both sides need to realise the mutual benefits of the hard work it takes to keep the relationship going.

Postgrad Med J 2004;80:251-252.

doi: $10.1136 /$ pgmi.2003.010504

Correspondence to: Dr Raj Persaud, Maudsley Hospital, Westways Clinic, 49 St James Road, Croydon CR9 2RR, UK; r.persaud@

iop.kcl.ac.uk

\section{REFERENCES}

1 Sweet $M$. Being a caring doctor may be bad for you. BMJ 2003;326:355

2 Jackson JL, Kroenke K. Difficult patien encounters in the ambulatory clinic: clinical predictors and outcomes. Arch Intern Med 1999:159:1069-75.

3 Werner A, Malterud K. It is hard work behaving as a credible patient: encounters between women with chronic pain and their doctors. Soc Sci Med (in press).

4 Bachman JW. The patient-computer interview: a neglected tool that can aid the clinician. Mayo Clin Proc 2003;78:67-78.

5 Ford S, Schofield T, Hope T. What are the ingredients for a successful evidence based patient choice consultation? A qualitative study. Soc Sci Med 2003;56:589-602.

6 Mead N, Bower P. Patient-centred consultations and outcomes in primary care: a review of the literature. Patient Education and Counselling 2002;48:51-61.

7 Aldrich KC. The medical interview: gateway to the doctor-patient relationship. 2nd Ed. New York: Parthenon Publishing Group, 1999.

8 Gray DP, Evans P, Sweney K, et al. Towards a theory of continuity of care. JR Soc Med 2003;96:160-6. 